\title{
XVIII. On certain modifications of a form of spherical integrator
}

\section{Frederick John Smith B.A.}

To cite this article: Frederick John Smith B.A. (1886) XVIII. On certain modifications of a form of spherical integrator, Philosophical Magazine Series 5, 22:135, 147-148, DOI: $10.1080 / 14786448608627912$

To link to this article: http://dx.doi.org/10.1080/14786448608627912

册 Published online: 08 Jun 2010.

Submit your article to this journal $[\pi$

Џ Article views: 2

Q View related articles $₫$ 
XVIII. On certain Modifications of a Form of Spherical Integrator. By Frederior JoHN Smith, B.A. Oxon. *

W

HILE working at the subject of Dynamometric Measurements, a great number of different forms of mechanical integrators were attached to a transmission-dynamometer (Phil. Mag. vol. xv. p. 87). In one of these the small disk of a Morin integrator (Phil. Mag. vol. xvii. p. 59) was replaced by a sphere carried between four little cylinders; the sphere was made of phosphorbronze (Ashmol. Soc. 1884).

As long as the dynamometer was driven with but little variation, the results were satisfactory; but as soon as one had to deal with quick variation, either of tension of belt or of velocity, it was found that the moment of inertia of the sphere was a serious obstacle to accurate results. It appeared probable that no instrument dependent npon the action of gravity could be relied upon. This being the case, it was evident that if a sphere was to be used it ought, in the first place, to be as light

Fig. 1.

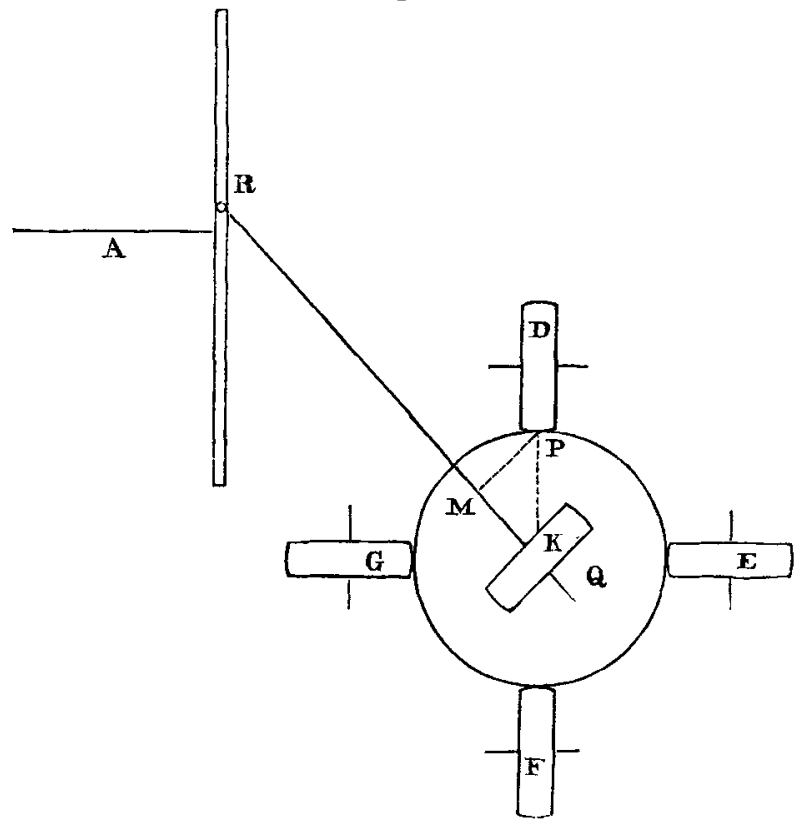

as practicable and, secondly, as firmly held as possible from any slip. These two ends have been arrived at as follows :-The sphere $\mathrm{Q}$ is made hollow in order to be light, and it moves between six wheels ; of these, four wheels, D E F G (fig. 1), are * Communicated by the Author.

$\mathrm{I} 2$ 
fixed upon a frame, while two others $K \mathrm{~L}$, held in a frame $S M N V$ (fig. 2) rocking about points at $S V$, keep the sphere Fig. 2.

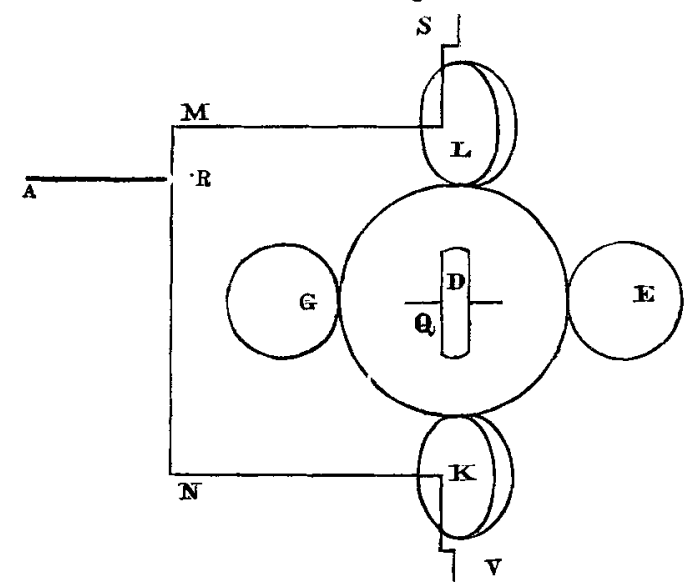

in compression ; the frame is so moved, by means of a slot $R$ attached to the spring rod of the dynamometer, that the line $P M$, and therefore the circle on the sphere rolling upon the cylinder $\mathrm{D}$, is proportional to the tension of the driving-belt; the cylinder $\mathrm{K}$ is driven at a rate proportional to the velocity of the belt-speed, and the cylinder $D$ is attached to a revolution-counter. When the tension of the belt is constant, then the revolution of $\mathrm{D}$ is proportional to the velocity. When the velocity is constant, the revolution is proportional to the tension of the belt. When both velocity and tension vary together, then the revolution of $D$ is proportional to the product of velocity and tension which is the work at any instant, and the number of revolutions of $D$ during any time is proportional to the work done during that time, and shows, therefore, how much energy has been transmitted by the dynamometer.

In the figures, for the sake of clearness, the frame which carries the cylinders is omitted. The instrument which the author of this communication has arrived at, is quite unaffected by any rapid change either of velocity or tension of belt that may take place while it is running. The beautiful three-wheel spherical integrator of Prof. Hele Shaw, which was applied to the dynamometer, as long as it had to deal with slowly varying velocity, acted very well indeed; the idea of changing the direction of the angle at which the poles of the sphere lie in is taken from it.

Algiers, March 1886. 